\title{
Woodflour as Reinforcement of Polypropylene
}

\author{
José Cláudio Caraschi ${ }^{\mathrm{a}}$, Alcides Lopes Leão ${ }^{\mathrm{b}}$ \\ ${ }^{a}$ Departamento de Química - Universidade Estadual de Maringá \\ ${ }^{\mathrm{b}}$ Departamento de Recursos Naturais - Faculdade de Ciências Agronômicas - UNESP
}

Received: November 13, 2000; Revised: September 01, 2002

\begin{abstract}
The effect of the filler content and size, as well as accelerated aging on the mechanical properties of polypropylene composites reinforced with woodflour (WF/PP) were evaluated. The composites were prepared by the extrusion of polypropylene with woodflour (Pinus elliotti) based on following ratios: 15, 25 and $40 \mathrm{wt} \%$ with two different granulometries. The specimens were injection molded according to ASTM standards. The composite properties did not show significant differences as a function of the filler granulometry. We also observed that by increasing the filler content, both the mechanical properties and the melt flow index (MFI) decreased, and the elasticity modulus, hardness and density increased. Concerning the accelerated aging, the composite presented a reduction in tensile properties. The results showed that the composite properties are extremely favorable when compared to other commercial systems reinforced by inorganic fillers.
\end{abstract}

Keywords: composites, polypropylene, woodflour and mechanical properties

\section{Introduction}

The use of natural fibers such as different plant fibers and wood fibers as reinforcement in thermoplastic, thermosets and elastomers has increased dramatically during the last years. With regard to the environmental aspects it would be very interesting if natural fibers could be used instead of inorganic fillers. Natural fibers have many advantages compared to those ones made by men, for example low density, low cost, non-abrasive, availability from renewable natural resources, they are recyclable and biodegradable. They are renewable raw materials and have relatively high strength and stiffness ${ }^{1-5}$.

On the other hand, there are also some disadvantages such as quality variations, moisture uptake and low thermal stability ${ }^{2,3}$. Many investigations about the potential of the natural fibers have been performed, and in several cases the results have shown that composite stiffness is good, however, the natural fiber composite does not reach the same strength level as glass fiber composites.

The use of wood fillers as reinforcement in thermoplastic polymer has become a topic of considerable interest due to the properties synergism ${ }^{1,2}$. Wood is an attractive reinforcement due to its low density, low cost, renewable and biodegradable character, and reasonable processibility.
Wood particles, such as chips, flakes, fibers, flour and wood pulps, are used as reinforcement agents. These types of natural fibers are able to satisfy both economical and ecological interests ${ }^{1-5}$.

Wood is a natural three-dimensional polymeric composite and consists primarily of cellulose, hemicelluloses, and lignin. These polymers build up the wood cell walls and cause most of their properties; even the undesirable ones, such as their hydrophilic nature and inherent polarity. The properties of wood, including its physical structure, mechanical properties, density and aspect ratio (average fibers length and diameter) change from species to species.

The objectives of the present study were to evaluate mechanical properties of the woodflour/PP composites and the influence of the reinforcement level and average particle size with and without accelerated aging on the mechanical properties.

\section{Experimental}

In this study, the base resin used was Fortilene 1602, a polypropylene homopolymer by Solvay Polymers with density of $0.89 \mathrm{~g} / \mathrm{cm}^{3}$ and melt flow index of $12.2 \mathrm{~g} / 10 \mathrm{~min}$.

The lignocellulosic material used as filler was woodflour (WF) of Pinus elliotti vary elliottii with apparent density of

*e-mail: jccaraschi@uem.br, alcidesleao@fca.unesp.br 
$0.374 \mathrm{~kg} / \mathrm{m}^{3}$, chemical composition of $50.1 \%$ cellulose, $30.3 \%$ lignin, $9.7 \%$ hemicelluloses and $10 \%$ of other contents. The WF was provided by Pinhopó-Moagem de Madeiras Ltda.

Blends containing PP with 15, 25 and $40 \%$ by weight of filler were prepared using woodflour of two different types of granulometry, 1040 mesh (diameter particle sizes between 0.1 and $0.05 \mathrm{~mm}$ ) and 90 mesh (diameter particle size between 0.2 and $0.1 \mathrm{~mm}$ ).

WF/PP composites were prepared in a twin-screw extruder, model ZSK-25, Werner \& Pfleiderer, L/D ratio of 25 , at $180 \mathrm{rpm}$ and the temperature profile of 190, 190, 180, 180 and $190{ }^{\circ} \mathrm{C}$ at zones $1,2,3,4,5$ and 6 (die zones), respectively.

The composites were granulated and dried at $105^{\circ} \mathrm{C}$ for $4 \mathrm{~h}$ to eliminate residual humidity from the fiber before the injection molding.

Injecting the composites at $190{ }^{\circ} \mathrm{C}$ molded the specimen and they were used for tensile and flexural properties evaluations, according to ASTM standards, in an automatic injection molder, Sandretto, 65 micro. For the evaluation of mechanical properties, virgin polypropylene (PP) and polypropylene with talc (Talc/PP), 20 and $40 \mathrm{wt} \%$, was injected as reference material.

All the obtained materials were kept at $25{ }^{\circ} \mathrm{C}$ with $25 \%$ humidity during $48 \mathrm{~h}$ before the mechanical testing. The performed testing was ASTM D638 ${ }^{6}$ for tensile strength, ASTM D790 7 for flexural strength and ASTM D2240 for Shore D hardness.

Tensile and flexural testing were performed using an EMIC Universal testing machine and Shore D hardness testing was performed using a Zwick machine. This testing was carried out at room temperature. The obtained results presented here are the average of five measurements obtained for each kind of sample.

The sample density was determined according to the ASTM D $1622^{9}$ at $25^{\circ} \mathrm{C}$ and the melt flow index (MFI) testing was performed in a plastometer with the extruded samples as in ASTM D1238 ${ }^{10}$

Accelerated aging of composites was carried out using an air oven at $70{ }^{\circ} \mathrm{C}$, during one week, following the procedures used in automotive industries for the evaluation of aged structural car parts.

\section{Results and Discussion}

Considering practical applications the polymers, mechanical properties are among the most important ones. It can be explained by the fact that most polymeric materials are used because of their good mechanical properties and low cost. Polymers present a wide variety of mechanical properties when compared to other materials. This variety depends on a great number of structural factors as molecu- lar mass, crosslinks and ramifications, cristallinity and crystalline morphology, co-polymerization, plastification, molecular orientation and reinforcement.

In this study the mechanical properties of composites with or without accelerated aging were evaluated, considering the reinforcement content and granulometry compared to non-reinforced PP and Talc/PP. The obtained results for tensile strength, tensile modulus and elongation at break are shown in Table 1.

The results showed that WF/PP composites presented tensile strength values lower than for PP; this occurs partly because of PP hydrophobic behavior, while the opposite happens to a natural fiber which has a good chemical affinity with water. This chemical incompatibility results in low interfacial adhesion between the thermoplastic layer and the fiber. The high cristallinity and high molecular mass of cellulose are likely to contribute to the weak chemical interaction between the two phases, therefore it is necessary to treat the fiber so that there is a better interaction between the cellulose and the matrix, or to use a bonding agent ${ }^{2}$. Tensile strength and elongation at break are extremely dependable properties on interfacial adhesion between the phases. If adhesion is not perfect, it is greatly likely that a gap will come up and the material will break in the interfacial region. The lack of adhesion makes this region weaker $^{1,2,11}$.

In relation to tensile modulus, the composites are more rigid than $\mathrm{PP}$, because the reinforcement is harder than the matrix and does not allow their free mobility, which avoids deformation, and therefore, increases the elasticity modulus as the fiber concentration increases.

Considering the used filler content (15, 25 and $40 \mathrm{wt} \%)$, it was verified that in all tested composites the tensile strength and elongation at break do not increase when compared to non-reinforced PP, while they gradually decrease with the increment of fiber mass in the composite. This small tensile strength decrease occurs with 15 to $25 \%$ of fiber concentration increase. That happens because the fiber adhesion to the matrix is not enough to increase of the matrix tensions transfer efficiency through the interface and that is essential to get an elevation of the mechanical properties in the composite. Kokta et al. ${ }^{12}$ also obtained similar results in which the increase of mass fiber amounts decreased the tensile strength and impact.

Concerning the particle size, it was observed that 1040 mesh provides greater tensile modulus and a smaller elongation at break to the composite in all analyzed cases. According to the literature ${ }^{1,2}$, the short and tiny fibers should be preferred. They provide a higher specific surface area, the fibers are distributed more homogeneously and so the compatibility of the fiber and matrix is improved. Kokta et al. ${ }^{12}$ related that the reinforced PP composites tensile 
strength was not affected significantly. These composites were reinforced with three types of woodflour: aspen, spruce and birch, with different fiber lengths. The tensile modulus increased with the fiber length. Similar results were obtained by Geethamma et al. ${ }^{13}$ when studying natural rubber composites reinforced with short coir fibers, and by Felix et al. ${ }^{(11)}$ using PP reinforced with paper filter. In relation to the melt flow index (Table 2), higher granulometry composites presented lower values, and considering hardness the results were similar.

Concerning the accelerated aging of composites, the results showed that there is a small reduction in the tensile strength and flexural modulus, while the elongation had a small increase because of the molecular chains splitting and

Table 1. Tensile mechanical properties of WF/PP composites with or without accelerated aging (comparison with data on commercially available polypropylene and composites); the values in parenthesis correspond to standard deviations of the measurements.

\begin{tabular}{lcccc}
\hline Materials & WF $(\%)$ & Tensile strength $(\mathrm{MPa})$ & Tensile modulus $(\mathrm{GPa})$ & Elongation at break $(\%)$ \\
\hline WF/PP & 15 & $27.13(0.30)$ & $2.38(0.29)$ & $4.24(0.13)$ \\
$(90$ mesh $)$ & 25 & $27.22(0.08)$ & $3.03(0.13)$ & $2.94(0.11)$ \\
& 40 & $24.42(0.27)$ & $3.63(0.15)$ & $2.05(0.12)$ \\
WF/PP & 15 & $25.46(0.25)$ & $2.00(0.11)$ & $3.34(0.13)$ \\
$(90$ mesh $)$ & 25 & $24.32(0.18)$ & $2.42(0.04)$ & $2.35(0.14)$ \\
aged & 40 & $21.79(0.78)$ & $2.84(0.08)$ & $4.06(0.23)$ \\
WF/PP & 15 & $28.22(0.30)$ & $2.48(0.09)$ & $2.68(0.08)$ \\
$(1040$ mesh $)$ & 25 & $27.32(0.32)$ & $3.32(0.16)$ & $1.85(0.11)$ \\
& 40 & $24.81(0.28)$ & $3.98(0.38)$ & $4.40(0.16)$ \\
WF/PP & 15 & $25.83(0.36)$ & $2.28(0.55)$ & $3.06(0.15)$ \\
$(1040$ mesh $)$ & 25 & $25.74(0.38)$ & $2.52(0.30)$ & $2.14(0.16)$ \\
aged & 40 & $23.77(0.19)$ & $3.24(0.14)$ & $14.6(0.50)$ \\
PP & 0 & $30.72(0.45)$ & $1.87(0.11)$ & $3.7(0.20)$ \\
PP (aged) & 0 & $28.31(0.14)$ & $1.58(0.06)$ & $2.04(0.10)$ \\
Talc/PP & 20 & $24.79(0.43)$ & $2.65(0.11)$ & 2.3 \\
& 40 & $22.43(0.32)$ & $4.35(0.20)$ & 2.5 \\
Mica/PP* & 40 & 39 & 7.60 & - \\
Glass fiber/PP* & 40 & 110 & 9.00 & \\
CaCO $/$ /PP* & 40 & 25 & 3.50 & \\
\hline
\end{tabular}

* Literature data ${ }^{15}$.

Table 2. Effect of woodflour contend and filler granulometry on the physical properties of WF/PP composites (comparison with data on commercially available polypropylene and composites); their respective values for standard deviations are in parenthesis.

\begin{tabular}{lcccccc}
\hline Materials & $\begin{array}{c}\text { WF } \\
(\%)\end{array}$ & $\begin{array}{c}\text { Density } \\
\left(\mathrm{g} / \mathrm{cm}^{3}\right)\end{array}$ & $\begin{array}{c}\text { MFI } \\
(\mathrm{g} / 10 \mathrm{~min})\end{array}$ & $\begin{array}{c}\text { Flexural strength } \\
(\mathrm{MPa})\end{array}$ & $\begin{array}{c}\text { Flexural modulus } \\
(\mathrm{GPa})\end{array}$ & Shore D Hardness \\
\hline WF/PP & 15 & $0.92(0.042)$ & 4.32 & $45.63(1.00)$ & $1.93(0.05)$ & $75.6(0.55)$ \\
$(90$ mesh $)$ & 25 & $0.95(0.026)$ & 3.84 & $45.57(0.25)$ & $2.47(0.04)$ & $75.8(0.84)$ \\
& 40 & $1.01(0.001)$ & 2.93 & $43.17(0.67)$ & $3.61(0.04)$ & $77.4(0.89)$ \\
WF/PP & 15 & $0.93(0.015)$ & 6.82 & $45.31(0.43)$ & $1.95(0.04)$ & $74.8(0.84)$ \\
$(1040$ mesh $)$ & 25 & $0.96(0.010)$ & 4.45 & $45.20(0.64)$ & $2.54(0.04)$ & $75.8(0.84)$ \\
& 40 & $1.20(0.030)$ & - & $44.18(0.16)$ & $3.48(0.05)$ & $77.2(1.10)$ \\
PP & 0 & $0.88(0.002)$ & 12.2 & $43.48(0.51)$ & $1.37(0.03)$ & $71.0(0.71)$ \\
Talc/PP & 20 & $1.03(0.007)$ & 16.8 & $38.34(0.42)$ & $1.97(0.07)$ & $72.6(0.48)$ \\
& 40 & $1.20(0.005)$ & 8.05 & $36.80(0.63)$ & $3.43(0.13)$ & $74.5(0.48)$ \\
Mica/PP* & 40 & 1.25 & - & 62 & 6.90 & - \\
Glass fiber/PP* CaCO $/$ PP* & 40 & 1.23 & - & 131 & 6.20 & - \\
\hline
\end{tabular}

* Literature data ${ }^{15}$. 
the formation of crosslinks in PP. These are factors that lead to the decrease of the mechanical properties.

The results for density, melt flow index, hardness and flexural properties are presented in Table 2.

In relation to flexural properties (Table 2), WF/PP composites presented higher strength and flexural modulus when compared to virgin and recycled PP.

Considering the hardness, all the composites were practically equivalent, that is, the composites presented similar values compared to non-reinforced $\mathrm{PP}$, and the composites presented a higher hardness because of the greater the reinforcement stiffness in relation to PP matrix.

Concerning the flow behavior, it was observed that MFI values of all studied composites decrease when there is an increase in fiber amount because the incorporation of rigid weight to the polymeric matrixes limits their free mobility, increasing the material apparent viscosity. This implies in a smaller MFI and is in accordance with to the literature data ${ }^{14}$.

WF/PP composites presented higher mechanical properties to the composites of Talc/PP (20 and 40\%) for tensile and flexural properties, although being less dense.

\section{Conclusions}

Based on the polypropylene composites reinforced with woodflour evaluation, it can be concluded that:

1. The composites presented inferior properties when compared to non-reinforced PP, and a decrease in mechanical properties as the fiber amount increased; it indicates that this behavior is associated to the low resistance of fiber-matrix interface and the incorporation of a bonding agent or fiber treatment is necessary when preparing any material that demand higher mechanical resistance;

2. It was verified that the composites presented small differences in their properties in relation to the reinforcement particle size; it was concluded that the tested granulometric variation does not significantly influence the evaluated mechanical properties;

3. Concerning the accelerated aging, it was concluded that the WF/PP composites showed a reduction in their tensile properties;

4. The WF/PP composites mechanical properties are extremely favorable when compared to other commercial systems reinforced with inorganic fillers (talc, calcium carbonate, mica, glass fiber, etc.). In general, the natural fibers cost is lower than the plastic one and high fiber loading can result in significant material cost savings. Nowadays the compounding is unlikely to be much higher than the conventional mineral/inorganic based one used by the plastic industry. Due to the woodflour's lower specific gravity (approximately 1.4 as compared to about 2.5 for mineral based systems), the composite properties, considering the composite weight, is an advantage that may have implications in the automotives and transportation applications. The applications of the composite tested are ideal for interior structural parts in the automotive industry.

5. Future research and development will lead to improvement concerning the quality of the product and an even wider range of applications.

\section{Acknowledgments}

The authors wish to thank Fundação de Amparo à Pesquisa do Estado de São Paulo (FAPESP) for the financial support to this work.

\section{References}

1. Bledzki, A.K.; Gassan, J. Composites reinforced with cellulose based fibres. Progress in Polymer Science, v. 24, p. 221-274, 1999.

2. Bledzki, A.K.; Reihmane, S.; Gassan, J. Thermoplastics Reinforced with Wood Fillers: A Literature Review. Polymer-Plastic Technology Eng., v. 37, n. 4, p. 451-468, 1998.

3. Rowell, R.M.; Sanadi, A.R.; Caulfield, D.F.; Jacobson, E. Utilization of Natural Fibers in Plastic Composites: Problems and Opportunities. In: Leão, A.L.; Carvalho, F.X. \& Frollini, E. eds. Lignocellulosic-Plastic Composites, São Paulo, USP \& UNESP, 1997. p. 23-51

4. Joseph, K.; Mattoso, L.H.C.; Toledo, R.D.; Thomas, S. Carvalho, L.H.; Pothen, L.; Kala, S.; James, B. Natural Fibers Reinforced Thermoplastic Composites. In: Frollini, E.; Leão, A.L.; Mattoso, L.H.C. eds. Natural Polymers and Agrobibers Based Composites. Embrapa Instrumentação Agropecuária Ed., São Carlos, SP. Section II - Agrofibers Composites, 2000. p. 159-201.

5. Leão, A.L.; Caraschi, J.C.; Tan, I.H.: Curaua Fiber - A Tropical Natural Fibers From Amazons Potential and Applications in Composites. In: Frollini, E.; Leão, A.L.; Mattoso, L.H.C. eds. Natural Polymers and Agrobibers Based Composites. Embrapa Instrumentação Agropecuária Ed., São Carlos, SP. Section II - Agrofibers Composites, 2000. p. 257-272.

6. ASTM D 638-90 - Standard Test Method for Tensile Properties of Plastics. Annual Book of ASTM, Philadelphia, $\mathrm{Pa}, 1990$.

7. ASTM D 790M-93 - Standard Test Method for Flexural Properties of Unreinforced and Reinforced Plastics and Electrical Insulating Materials [Metric]. Annual Book of ASTM, Philadelphia, Pa, 1993.

8. ASTM D 2240 - Standard Test Method for Rubber Property - Durometer Hardness. Annual Book of ASTM, Philadelphia, $\mathrm{Pa}$.

9. ASTM D 1622 - Standard Test Method for Standard Test 
Method for Apparent Density of Rigid Cellular Plastics. Annual Book of ASTM, Philadelphia, Pa.

10. ASTM D 1238-90b - Standard Test Method for Flow Rates of Thermoplastics by Extrusion Plastometer. Annual Book of ASTM, Philadelphia, Pa, 1991.

11. Felix, J.M.; Gatenholm, P. The Nature of Adhesion in Composites of Modified Cellulose Fibers and Polypropylene. J. Appl. Polym. Sci., v. 42, n. 3, p.620609, 1991.

12. Kokta, B.V.; Raj, R.G.; Daneault, C. Use of Wood Flour as a Filler in Polypropylene: Studies on mechanical properties. Polym.-Plast. Technol. Eng., v. 28, n. 3, p.
247-259, 1989.

13. Geethamma, V.G.; Joseph, R.; Thomas, S. Short Coir Fiber-Reinforced Natural Rubber Composites: Effects of Fiber Length, Orientation, and Alkali Treatment. $J$. Appl. Polym. Sci., v. 69, n. 4, p. 583-584, 1995.

14. Basu, D.; Banerges, A.N.; Misra, A. Comparative Rheological Studies on Jute-Fiber an Glass-Fiber-Filler Polypropylene Composites Melts. J. Appl. Polym. Sci., v. 46, p. 1999-2002, 1992.

15. Sanadi, A.R.; Jacobson, E.; Caulfield, D.F.; Rowell, R.M. Renewable Agricultural Fibers as Reinforcing Fillers in Plastics. Ind. Eng. Chem. Res., v. 34, p. 1889, 1995. 